\title{
Balance del Foro de Vivienda y Rehabilitación de BARCELONA (FHAR)
}

\section{Review of the Barcelona Housing and Renovation Forum (FHAR)}

\author{
Diego Miralles Buil ${ }^{1}$ \\ Fecha de recepción: 15-05-2019 - Fecha de aceptación: 12-09-2019 \\ Hábitat y Sociedad (ISSN 2173-125X), n. ${ }^{\circ}$ 12, noviembre de 2019, pp. 123-133. \\ http://dx.doi.org/10.12795/HabitatySociedad.2019.i12.08
}

\begin{abstract}
Organized by the Municipal Institute of Housing and Renovation of Barcelona (IMHAB), the FHAR took place from March 19 to 21, 2019 at the Auditorium of the Museum of Contemporary Art of Barcelona (MAC$\mathrm{BA})$. The objective of the forum was to discuss the issue of housing law, gathering subject specialists coming from various local, regional, national and international administrations, as well as private sector professionals, researchers and members of social movements. This article aims to review this remarkable event with many round tables and interesting debates to understand the current situation of the housing issue in Barcelona. It makes a synthesis of the presentations of each table and as a conclusion, recall the great challenges that the forum put in evidence and shows the points of encounter and conflicts.
\end{abstract}

Key words

Right to housing; Barcelona; Social Housing; Habitat; Architecture; Urbanism

\section{Resumen}

Organizado por el Instituto Municipal de la Vivienda y Rehabilitación de Barcelona (IMHAB), el FHAR tuvo lugar del 19 al 21 de marzo de 2019 en el Auditorio del Museo de Arte Contemporáneo de Barcelona (MACBA). El objetivo del foro era debatir sobre el derecho de la vivienda, reuniendo tanto especialistas del tema de varias administraciones locales, autonómicas, nacionales e internacionales, así como profesionales del sector privado, investigadores y miembros de los movimientos sociales. Este artículo propone una reseña de este evento que constó de muchas mesas redondas y debates interesantes para entender la situación actual del tema de la vivienda en Barcelona. Se hará una síntesis de las ponencias de cada mesa y a modo de conclusión, se recogerán los grandes retos que puso en evidencia el foro, evidenciando los puntos de encuentro y conflictos.

\section{Palabras clave}

Derecho a la vivienda; Barcelona; Vivienda Social; Hábitat, Arquitectura; Urbanismo

1 Doctorando en Geografía, Planificación y Urbanismo y miembro de la cátedra de investigación "Habiter ensemble la ville de demain" Chaire HEVD del LabEx Intelligences des Mondes Urbains (IMU). Casa de Velázquez (EHEHI), Ciudad Universitaria, Calle Paul Guinard, 3, 28040 Madrid. E-mail: diego.mirallesbuil@casadevelazquez.org 


\section{Introducción}

Del 19 al 21 de marzo de 2019, el Institut Municipal de l'Habitatge $i$ Rehabilitació de Barcelona (IMHAB) organizó el primer Foro de Vivienda y Rehabilitación de Barcelona (FHAR) que tuvo lugar en el Auditorio del MACBA. Su objetivo era debatir sobre el tema de la vivienda, reuniendo especialistas de varias administraciones públicas (municipales, autonómicas, nacionales e internacionales), profesionales del sector privado, investigadores y miembros de colectivos militantes. Se organizaron varias mesas temáticas, presentaciones de proyectos y debates con la sala, repartidos en cinco bloques (Figura 1). En esta reseña, presentaremos las ponencias siguiendo la estructura del foro para poder analizarla. ${ }^{2}$ A modo de conclusión, recogeremos los grandes retos que

\section{MARTES 19}

$18.00-20.00$

Retos globales y soluciones

locales al derecho de la vivienda

Raquel RoInik, profesora de la facultad de arquitectura y urbanismo de la

Universidad de São Paulo

Josep Maria Montaner, concejal de Vivienda y Rehabilitación de Ayuntamiento de Barcelona

Modera: Cristina Fallarás, periodista y escritora

\section{MEREOLLS 20}

\section{PLANIFICAR LAS POLITICAS} DE VIVIENDA

$9.15-11.00$

Medir para planificar. La generación de indicadores y presentación del estado de la cuestión

Carme Trilla, presidenta del Observatorio Metropolitano de la Vivienda de Barcelon Mario Yoldi, director de Planificación y Procesos Operativos de Vivienda del gobierno vasco

Modera: Beatriz Toribio, directora de estudios de Fotocasa

11.00 Pause

$11.30-13.30$

El rol de las administraciones ante la crisis de acceso a la

vivienda en las ciudades

Javier Martin Ramiro, director general

de Arquitectura, Vivienda y Suelo del Mi-

nisterio de Fomento

Agusti Serra, secretario de Hábitat Urbano

y Territorio de la Generalitat de Catalunya
Javier Burón, gerente de Vivienda y Rehabilitación del Ayuntamiento de Barcelona

Modera: Irene Peiró, periodista

13.30 Comida

\section{CREAR Y REPENSAR} EL PARQUE DE VIVIENDA

ASEQUIBLE

$15.00-16.00$

Presentación de los finalistas del BCN-NYC Challenge

Anna Majó, directora de Innovación Digital del Ayuntamiento de Barcelona

Eduard Cabré, coordinador de Relaciones Internacionales de la gerencia de la Vivienda y Rehabilitación de Barcelona $16.00-17.30$

Vivienda intergeneracional. Aproximaciones a las diferentes necesidades vitales

Gaspar Mayor, gerente del Patronato Municipal de la Vivienda de Alicante Zaida Muxi, arquitecta y autora del libro Mujeres, Casas y Ciudades

Ana Fernández, arquitecta en Cohousing Lab

Modera: Laia Grau, arquitecta y urbanista

17.30 Pausa

$18.00-20.00$

Work in progress

Presentación de seis proyectos de obra nueva y rehabilitación de vivienda publica de Barcelona a cargo de sus arquitectos Modera: Joan Carles Melero, director de los Servicios Técnicos del IMHAB

\section{JUEVES 21}

\section{RESPONDER \\ A LA EMERGENCIA}

Respuestas a la emergencia prevenir, parar, alojar Judith Cobacho, SIPHO y Asociación Vincle Lucía Delgado, portavoz de la PAH Barcelon Fernando Diaz, representante de Cáritas Modera: Maria Assumpció Vilà, síndica de agravios de Barcelona 11.00 Pausa

\section{COPRODUCIR CON}

OTROS AGENTES

\section{Coproducción con empresas sin} ánimo de lucro o lucro limitado Ricard Fernández, gerente de Derechos Sociales del Ayuntamiento de Barcelona Gerald Koessl, representante de la Austrian Federation of Limited Profit Housing Associations

Modera: Anna Gener, presidenta de Aguirre Newman

Coproducción comunitaria: cooperativas en cesión de uso y community land trusts Joaquin de Santos, responsable del proyecto europeo Sustainable Housing for Inclusive and Cohesive Cities (SHICC) de Community Land Trust Bruxelles (CLTB) Maria Antònia Garcías Roig. gerente del Instituto Balear de la Vivienda (IBAVI) Vanesa Valiño, jefa de gabinete de la Concejalia de Vivienda y Rehabilitación del Ayuntamiento de Barcelona Modera: Mara Ferreri, investigadora posdoctoral en el IGOP (UAB)

REGULAR EL MERCADO
Lomida
Lucha contra la gentrificación
David Bravo, arquitecto y asesor del
Ayuntamiento de Barcelona
Rui Neves Bochmann Franco, concejal
de Vivienda y Desarrollo Local del
Ayuntamiento de Lisboa
Modera: Núria Benach, profesora titular
de Geografí de la UB y miembro de
Espais Critics
16.00-17.30
La colaboración y el control para
garantizar el buen Uso de la vivienda
Fuensanta Alcalá, directora técnica de
la Unidad de Disciplina de Vivienda del
IMHAB
Joan Manel González, arquitecto municipal
en Santa Coloma de Gramenet
Núria Pedrals, arquitecta
Modera: Josep Casas, arquitecto,
codirector del Posgrado en Politicas
de Vivienda (COAC)
17.30 Pausa
18.00 - 20.00
Generación de alquiler asequible
Bojan Schnabl, coordinador de la EUUA
Housing Partnership
Reiner Wild, director ejecutivo del
Mieterverein Berlin
Jaime Palomera, portavoz del Sindicato
de Inquilinos de Barcelona
Elga Molina, responsable de la Bolsa de
Alquiler social del Consejo Comarcal del
Tarragonés, doctora en Derecho y profe-
sora asociada de Derecho Civil de la URV
Modera: Cristina Fallarás, periodista
y escritora

2 Por cuestiones de espacio, no podremos presentar precisamente todas las ponencias. Nos centraremos en las ponencias que nos parecieron más interesantes respecto a la actualidad del tema. Para los lectores que quieran obtener más informaciones, agrupamos todos los videos y archivos de presentación de los ponentes en la página web: https://antreautre.hypotheses.org/862.

\section{Conferencia inaugural: Retos globales y soluciones locales al derecho de la vivienda}

El FHAR arrancó con un debate entre Raquel Rolnik (ex-relatora de la ONU para la vivienda) y Josep María Montaner (concejal de Vivienda y Rehabilitación del Ayto. de Barcelona de 2015 a 2019) sobre los retos globales y las soluciones locales para defender el derecho a la vivienda (Figura 2). 


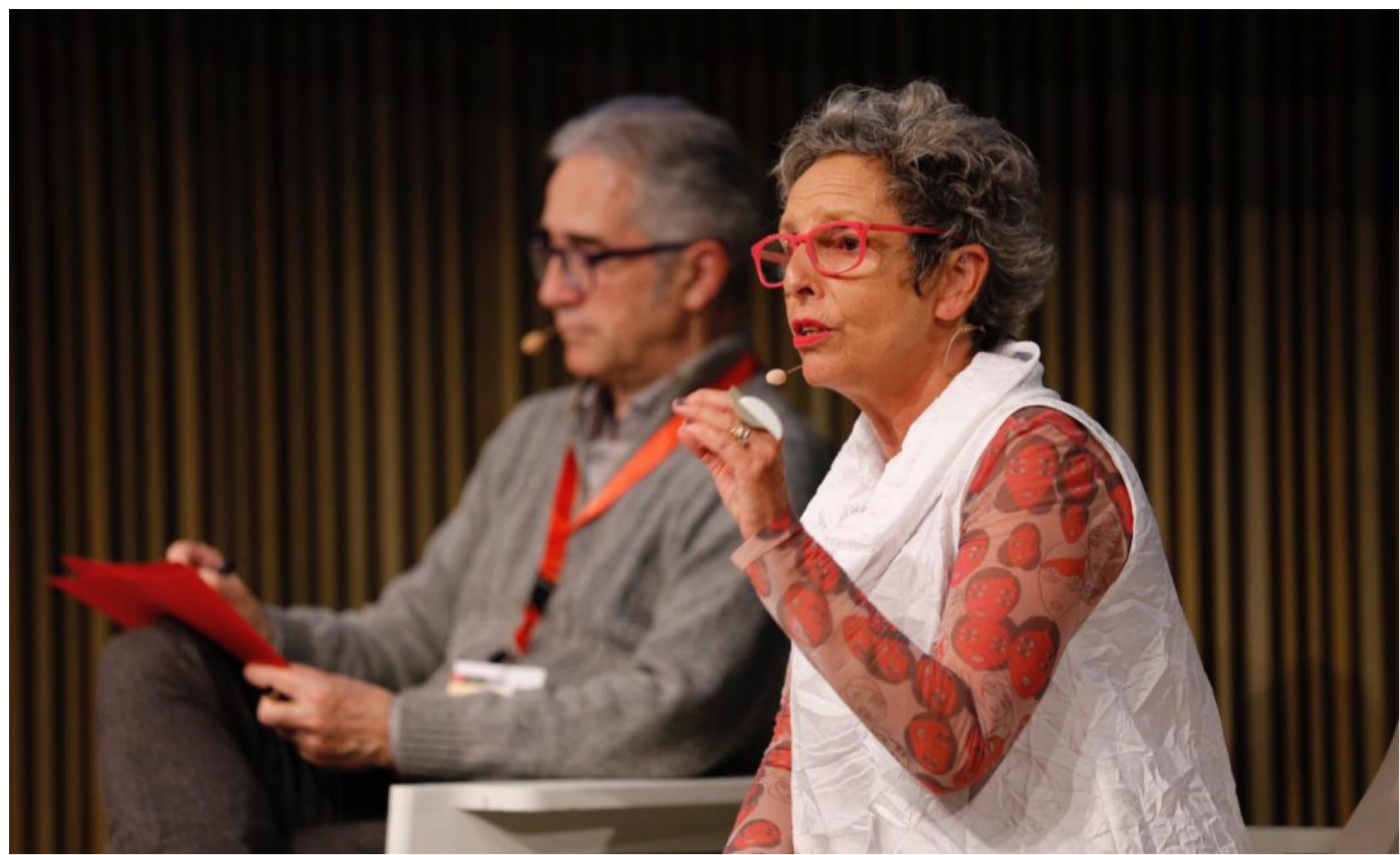

Según Rolnik, la crisis actual de la vivienda que vive Barcelona es un problema global: las ciudades enfrentan un "nuevo poder colonial" constituido por fondos de inversión y grandes grupos financieros que "colonizan los espacios de los individuos y están reestructurando las ciudades". Afirmó que vivimos un proceso de desterritorialización donde las viviendas y el territorio se transforman en activos financieros mediante el proceso de titularización. Distinguió una primera ola de desposesión (ejecuciones hipotecarias) y una segunda ola que afecta ahora a los inquilinos viviendo en el centro de la ciudad ${ }^{3}$ (Rolnik, 2018). También señaló la importancia de las especificidades locales: todo depende de los actores y del mercado local de la vivienda. Añadió que, si bien son las ciudades las que hoy enfrentan este problema, la solución tendría que venir de todos los niveles de gobierno: "el Estado tendría que regular el mercado financiero y, al nivel local, los habitantes tendrían que presionar a los actores públicos”.

J. M. Montaner insistió en el atraso español, comparando Barcelona con otras ciudades europeas como París, Berlín, Viena o Londres y haciendo hincapié en la necesidad de "alcanzar los estándares europeos en materia de vivienda". Por eso, durante el mandato 2015-2019, el Ayto. de Barcelona impulsó nuevas construcciones, vivienda en alquiler, covivienda, rehabilitación y actuó en el tema del turismo. ${ }^{4}$ También presentó la Modificación del Plan General Metropolitano (MPGM) que fue aprobada por el mismo ayuntamiento gracias al impulso de varios colectivos sociales y que obliga a los promotores de promociones y rehabilitación residenciales de más de $600 \mathrm{~m}^{2}$ a destinar un $30 \%$ de la superficie a viviendas protegidas. ${ }^{5}$ Concluyó su ponencia reafirmando la voluntad del Ayto. de seguir luchando contra los desahucios, la especulación y el acoso inmobiliario. ${ }^{6}$

Durante el debate, Rolnik abogó por los proyectos de vivienda cooperativa y autogestionada como unas de las esperanzas más potentes
Figura 2: Raquel Rolnik y Josep María Montaner durante el debate. Fuente: $<$ <ttps://habitatge.barcelona>

3 Según Rolnik, los actuales procesos de gentrificación en muchas metrópolis del mundo son una materialización de esta segunda ola de desposesión (Rolnik, 2018).

4 Con el Plan Especial Urbanístico de Alojamientos Turísticos (PEUAT), que tenía como objetivo frenar la implantación de hoteles en la ciudad y regular los pisos turísticos.

5 Más informaciones sobre esta medida en: www.huit.re/MPGM-30.

6 Más informaciones sobre las políticas de vivienda en Barcelona en el libro publicado en la ocasión del FHAR: "Innovación en vivienda asequible. Barcelona 2015-2018” (Hernández Falagán, 2019). 
para defender el derecho a la vivienda y a la ciudad (Lefebvre, 1968) y criticó las políticas de vivienda impulsadas por los Estados que no toman en cuenta los deseos de los ciudadanos. Según ella, "la forma de organización del Estado es una forma que desde su nacimiento tiene que ver con la expansión de los mercados y las relaciones mercantiles. Lo 'público' es propiedad privada del Estado y no propiedad común de los ciudadanos". Hizo referencia a las viviendas públicas que se privatizaron en Madrid (bajo mandato del Partido Popular), señalando que por esta razón el alquiler público convencional no es la solución. Defendió las cooperativas gestionadas colectivamente bajo la lógica del "común" (Dardot y Laval, 2015). Según ella, "los actores públicos tienen que dar más recursos, asistencia técnica y poder a la gente que ya está construyendo su propia ciudad y su propio hábitat". Concluyó que era una de las principales vías para luchar contra los procesos de desposesión territorial, una vía que podrá permitir un mejor acceso a la vivienda y una reapropiación del sector de la vivienda y del territorio por parte de los habitantes. ${ }^{7}$

\section{Planificar las políticas de vivienda}

En la primera mesa de la sesión 1, "Medir por planificar. La generación de indicadores y presentación del estado de la cuestión", Carme Trilla, presidenta del Observatori de l'Habitatge de Barcelona (de aquí en adelante O-HB) y Mario Yoldi, director de Planificación y Procesos Operativos de Vivienda del Gobierno vasco, insistieron en la necesidad de tener datos fiables para desarrollar políticas de vivienda territorializadas. Trilla presentó los resultados de varios estudios del OHB, una entidad impulsada por el ayuntamiento, el Área Metropolitana, la Diputación de Barcelona y la Generalitat de Catalunya con el objetivo de mejorar los datos existentes sobre la situación de la vivienda en Barcelona. Yoldi se centró en el uso de los datos hecho por parte del Gobierno vasco con el fin de ajustar su política de vivienda a las demandas de los habitantes y acercarse a las necesidades de cada municipio o barrio. Además, defendió la importancia de los procesos de participación ciudadana para una buena territorialización de las políticas de vivienda.

En la segunda mesa, sobre el "Rol de las administraciones ante la crisis de acceso a la vivienda en las ciudades", los representantes del Estado español (Javier M. Ramiro, Ministerio de Fomento), de la Generalitat (Judith Gifreu, directora de la Agencia de la Vivienda) y del Ayto. de Barcelona (Javier Burón, gerente de Vivienda) discutieron del "rol de las administraciones ante la crisis de acceso a la vivienda en las ciudades" (Figura 3). En el tema de la "crisis de los alquileres" nos encontramos con dos puntos de vista enfrentados: por un lado, los representantes del Estado y de la Generalitat que coincidían en la importancia de tener un índice de referencia de precios de alquiler y por otro lado Burón (Ayto. de Barcelona) quién defendía una regulación más estricta de los precios siguiendo los ejemplos de Alemania o Francia. Sin embargo, los tres ponentes estuvieron de acuerdo sobre muchos otros temas: aumentar la oferta de vivienda en alquiler para bajar los precios; apostar por la colaboración público-privada y por una corresponsabilización del sector privado; desarrollar medidas financieras para construir nuevas viviendas con incentivos fiscales. Para aumentar el parque de vivienda asequible, todos insistieron en la importancia de aumentar el presupuesto público (estatal y autonómico) en materia de vivien-

7 Así, Rolnik demostró un fuerte lazo conceptual con los pensadores libertarios del urbanismo como, por ejemplo, el arquitecto John F. C. Turner (Turner et al., 2018). 
da y de aumentar la construcción de vivienda. Burón se distinguió de los otros ponentes con una propuesta que consiste en combinar medidas restrictivas (para obligar a los actores privados a limitar los precios) con una "colaboración respetuosa" con el sector privado. Esta propuesta pareció contradictoria para algunos oyentes de la sala, y el tema se volvió a colocar en el debate, cuando varios promotores y arquitectos evocaron la falta de negociación y de participación del sector privado a la hora de desarrollar políticas públicas de vivienda en Barcelona. ${ }^{8}$

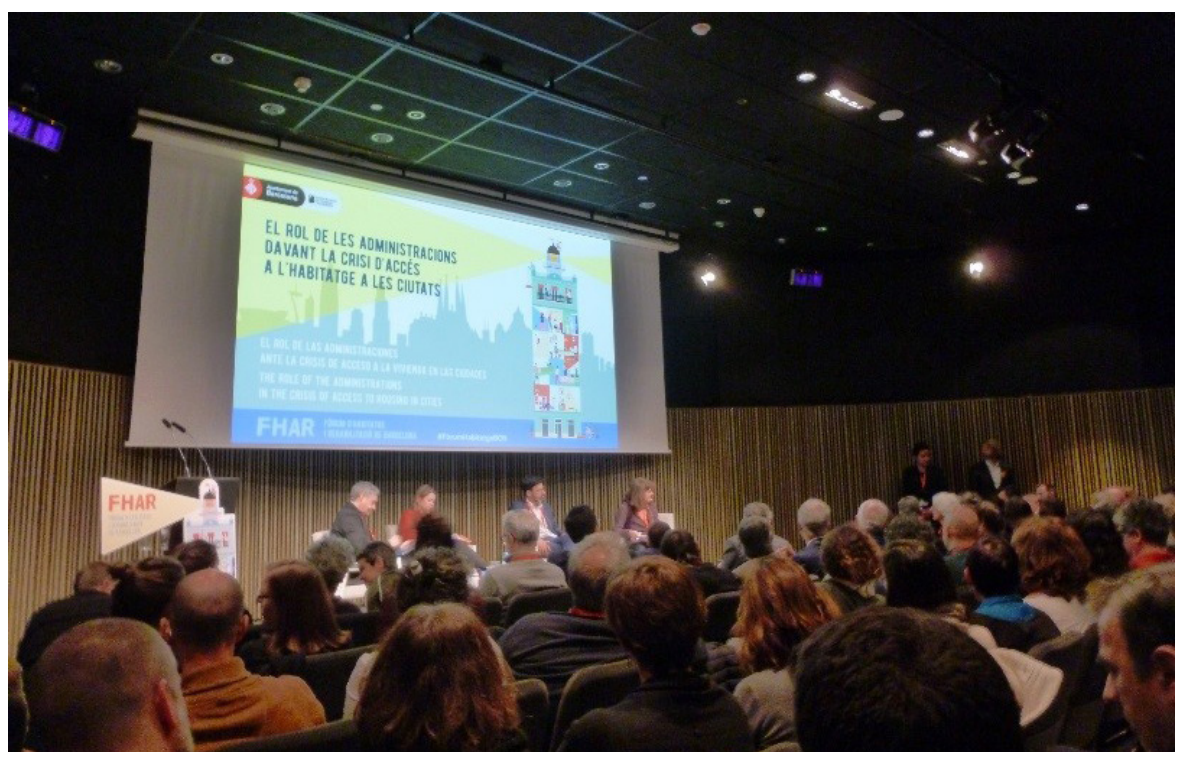

\section{Crear y repensar el parque de vivienda asequible}

En la mesa sobre "Vivienda intergeneracional. Aproximaciones a las diferentes necesidades vitales", los ponentes reafirmaron la necesidad de tomar en cuenta y de anticipar los cambios sociales y culturales en la construcción de vivienda y presentaron algunos proyectos de viviendas intergeneracionales. La arquitecta Ana Fernández, co-creadora del cohousing_LAB, presentó unos proyectos holandeses de asociaciones de vivienda que tienen un éxito importante (Figura 4). Estas asociaciones (algunas de ellas con más de 120 años de funcionamiento) reciben ayudas del estado (económicas y fiscales) y gestionan el $60 \%$ de la vivienda social de alquiler en las grandes ciudades de Holanda. Tras presentar unas iniciativas en Alicante, Gaspar Mayor, gerente del Patronato Municipal de la Vivienda de Alicante, destacó el valor de los proyectos de viviendas intergeneracionales para ofrecer un apoyo logístico y una mejor calidad de vida a las personas mayores. Finalmente, Zaida Muxí, experta en cuestiones de Espacio y Genero, defendió la incorporación de una perspectiva feminista en los proyectos de arquitectura para poder adaptar las viviendas a las diferentes etapas de la vida (Muxí, 2018).

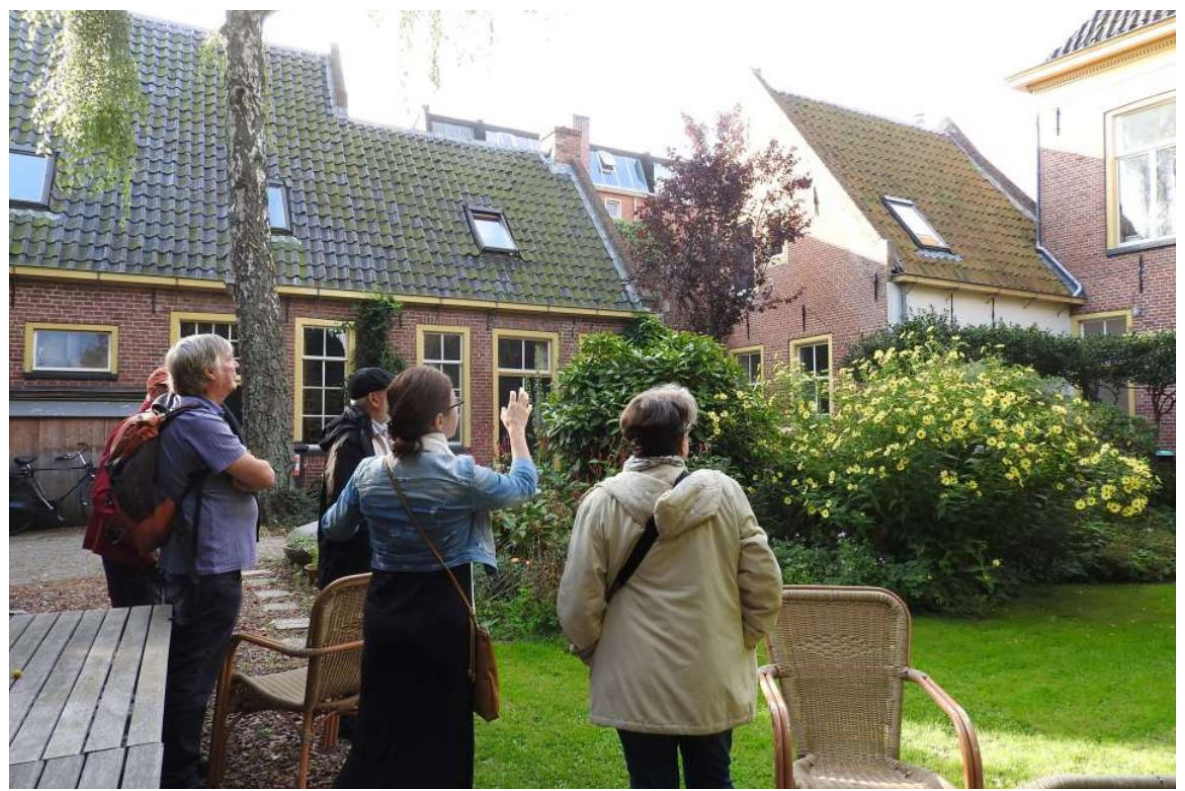

Figura 3: Debate de la mesa sobre el "rol de las administraciones". Fuente: Autor.

Figura 4: Proyecto de una asociación de vivienda holandesa (1976) presentado por Ana Fernández. Fuente: cohousing_LAB. 


\section{Responder a la emergencia}

La mesa "Respuestas a la emergencia: prevenir, parar, alojar" trató de diferentes maneras de responder a la emergencia habitacional en Barcelona. Judith Cobacho presentó el funcionamiento del SIPHO,${ }^{9}$ un servicio externalizado del Ayto. de Barcelona, creado en 2015 y cuyo trabajo consiste en mediar entre las personas en riesgo de desahucio y los propietarios, acompañar a las familias e intentar bloquear los lanzamientos antes que sucedan. Lucía Delgado presentó la Plataforma de Afectados por la Hipoteca (PAH), su evolución, sus luchas y su voluntad de promover cambios legales estructurales para mejorar el derecho a la vivienda en España. Fernando Díaz, de Cáritas Barcelona, explicó cómo su entidad acompaña a las personas en casos de emergencia habitacional para ayudarlas a encontrar una solución (alquiler social, mesa de emergencia, etc.) y cómo colabora con las administraciones públicas para gestionar la vivienda social. Acabada la mesa, se abrió un debate entre varias personas de la sala sobre las nociones de empoderamiento/asistencialismo y sobre el papel de las instituciones y de los movimientos sociales en el empoderamiento de los habitantes. En este aspecto se notó una divergencia significativa entre los ponentes de la mesa y unos miembros de colectivos barriales presentes en la sala que defendieron la autonomía de los colectivos militantes y criticaron la "cooptación estructural" de los movimientos sociales por parte de las instituciones (Lopes de Souza, 2006).

\section{Coproducir con otros agentes}

En la mesa "Coproducción con empresas sin ánimo de lucro o lucro limitado”, Ricard Fernández (gerente de Derechos Sociales del Ayto. de Barcelona) y Gerald Koessl (representante del Austrian Federation of Limited Profit Housing Associations, GBV) defendieron la importancia de la colaboración público-privada para mejorar el acceso a la vivienda. Desde 2015, el Ayto. de Barcelona puso en marcha varios proyectos de coproducción de vivienda con el sector privado: concursos de solares en derecho de superficie para cooperativas, fundaciones y empresas; convenios con entidades como Habitat3, Cáritas y entidades inmobiliarias con el objetivo de aumentar el parque de vivienda social y asequible; convenios de cesión y gestión de vivienda con grandes tenedores. Además, con el impulso del Ayto. y del Área Metropolitana de Barcelona, se creó un operador público-privado de vivienda (Habitatge Metròpolis Barcelona) con el objetivo de construir vivienda asequible en alquiler. ${ }^{10}$ Según R. Fernández, tales colaboraciones son imprescindibles para llevar a cabo una política de vivienda ambiciosa, ya que los costes de construcción no pueden ser únicamente sostenidos por el sector público. Finalmente, insistió en la necesidad de poner en marcha políticas que recompensen las empresas privadas que construyan vivienda asequible y de obtener más financiación por parte de las administraciones supramunicipales para apoyar la colaboración público-privada. Koessl presentó el caso de la GBV y de las 185 asociaciones de vivienda que la compone. Esta federación de asociaciones recibe un tratamiento fiscal muy favorable y es una de las vías más importantes de producción de vivienda asequible (mediante construcción nueva y rehabilitación). Pero pese a que el precio de alquiler se sitúe por debajo del precio del mercado libre, estas vivien-

$9 \quad$ Servicio de Intervención y mediación ante situaciones de Pérdida de Vivienda y Ocupaciones.

101500 viviendas previstas en Barcelona y 1500 más en el resto del Área Metropolitana en 5 años. 
das financiadas por fondos públicos parecen más bien destinadas a la clase media (Reinprecht, 2010).

A continuación, en la mesa sobre "Coproducción comunitaria: cooperativas en cesión de uso y Community Land Trusts (CLT)" Joaquim De Santos (responsable del proyecto europeo SHICC y CLT de Bruselas) presentó el modelo de CLT, una organización sin ánimo de lucro que obtiene suelos y edificios para gestionarlos bajo el beneficio de la comunidad y de manera antiespeculativa. También presentó el caso del CLT de Bruselas impulsado por la sociedad civil, con 120 viviendas previstas repartidas en 9 proyectos. ${ }^{11}$ Según De Santos, los CLT son interesantes porque permiten producir vivienda asequible y crear comunidad, y porque no se pueden privatizar fácilmente con un cambio de gobierno. La dificultad radica en adaptar el modelo de CLT al marco jurídico de cada país. En la misma mesa, Maria Antònia Garcías Roig (gerente del IBAVI) y Vanesa Valiño (jefa de gabinete de la Concejalía de Vivienda y Rehabilitación del Ayto. de Barcelona) presentaron los concursos públicos de cesión de solares a cooperativa de vivienda en cesión de uso (covivienda) con titularidad colectiva y suelo público impulsado por el Instituto Balear de la Vivienda (IBAVI) y el Ayto. de Barcelona. ${ }^{12}$ En estos proyectos, la administración sigue controlando el proyecto para comprobar que cumpla los requisitos pactados. En la línea de la conferencia de Rolnik, V. Valiño defendió el desarrollo de esta forma de urbanismo autogestionado, un nuevo modelo de vivienda que lucha contra la especulación y crea comunidad y empoderamiento.

\section{Regular el mercado}

En la primera mesa de la última sesión del FHAR sobre la "Lucha contra la gentrificación", el concejal de Vivienda y Desarrollo Local del Ayto. de Lisboa (Rui Neves Bochmann Franco) explicó que muchos lisboetas tuvieron que irse del centro de la ciudad por culpa de la presión turística y propuso hacer pagar impuestos a las plataformas de vivienda turísticas como Airbnb para luchar contra la gentrificación. Según el arquitecto David Bravo, quién tomó la palabra después, sería necesario comprender bien las distintas formas de gentrificación ${ }^{13}$ y producir estudios y datos sobre este fenómeno en Barcelona para tener una mirada más comprensiva y transversal (multisectorial y trans-administración). Según Bravo, el papel de la arquitectura y del urbanismo es central para solucionar el problema y, durante su ponencia, criticó abiertamente el filósofo Richard Sennett que afirma en su último libro que no se puede combatir las desigualdades urbanas solo desde la arquitectura y el urbanismo (Sennett, 2019). Para Bravo, la solución sería "construir más y mejor". Los dos ponentes afirmaron también que el papel de los movimientos sociales era fundamental y que las cooperativas de vivienda y el derecho de tanteo y retracto por parte del Ayto. podrían ser soluciones interesantes para combatir la gentrificación.

En la penúltima mesa, titulada "La colaboración y el control para garantizar el buen uso de la vivienda", se debatió cómo garantizar el buen uso de las viviendas y luchar contra las "anomalías" (como viviendas vacías, fraudes de vivienda protegida, ocupaciones ilegales, etc.). Fuensanta Alcalá (directora técnica de la Unidad de Disciplina de Vivienda del IMHAB), presentó cómo entre 2015 y 2019 el Ayto. de Barcelona prestó una gran atención en la disciplina y el buen uso de las viviendas con una idea clave: "regular y normalizar el mercado". Por eso,
11 Más información en: www.cltb.be 12 Cinco solares (117 viviendas previstas) en el caso del IBAVI en 2019; siete solares (133 viviendas previstas) en 2016 por parte del Ayto. de Barcelona (de los cuales solo cinco solares -110 viviendas- fueron realmente impulsado). En 2019, el Ayto. de Barcelona impulsó un segundo concurso con otros tres solares municipales.

13 Según J. Sequera y J. Nofre (2018), existe una confusión muy común en los estudios de gentrificación, mezclando dos procesos distintos que son la gentrificación y la turistificación. 
puso en aplicación la Ley catalana del Derecho a la Vivienda (18/2007) que defiende la función social de la vivienda pero que no se aplicaba correctamente hasta entonces. Añadió que para garantizar el buen uso de la vivienda hay que tener datos fiables del sector de la vivienda y, sobre este tema, felicitó el trabajo del Observatori de l'Habitatge de Barcelona. Los arquitectos Núria Pedrals y Joan Manel González presentaron respectivamente la gestión de la rehabilitación (estructural y energética) de los Aytos. de Barcelona y de Santa Coloma de Gramenet. Señalaron la escasez de financiamiento y la dificultad de los municipios y de las comunidades de vecinos para acceder a ayudas de rehabilitación. Reivindicaron más esfuerzo financiero por parte de las administraciones supramunicipales para apoyar la rehabilitación y para poder territorializar las políticas de vivienda.

En la última mesa del foro, "Generación de alquiler asequible", los mecanismos de regulación de precio del alquiler fueron el tema central. Elga Molina (Doctora en Derecho y responsable de la Bolsa de Alquiler Social del Consejo Comarcal del Tarragonés) presentó las políticas de alquiler de varios países europeos con contratos de alquileres indefinidos y los mecanismos de regulación del precio del alquiler de Francia y Alemania. Bojan Schnabl (coordinador de la EUUA Housing Partnership) presentó el caso de Viena, una ciudad que lleva una larga tradición en vivienda social con mecanismos de control público del alquiler. Como en Francia y Alemania, el modelo "generalista" de vivienda social de Viena toma en cuenta un público amplio pero circunscrito mediante la definición de tope de renta y de criterios de prioridad (Ghekière, 2008; Lévy-Vroelant y Tutin, 2010). El caso de Berlín, con sus $85 \%$ de vivienda en alquiler, fue presentado por Reiner Wild (director ejecutivo del sindicato de inquilinos de Berlín). Según él, el mecanismo de regulación de los precios de los alquileres en vigencia en Berlín no funciona correctamente: a pesar de este sistema de regulación, el precio de los alquileres de Berlín aumentó del 100\% en los últimos diez años. Según Wild, hay muchas maneras de esquivar este sistema, ${ }^{14}$ lo que demuestra que la regulación de precios de alquiler no funciona bien. Según él, "hay que encontrar otras maneras de defender el acceso a la vivienda digna". Actualmente en Berlín se promueve cooperativas y otras organizaciones autónomas sin ánimo de lucro para aumentar el stock de vivienda asequible y se piensa promover un referéndum para aprobar la expropiación de pisos de grandes tenedores para convertirlos en alquiler social. Contrarrestando con el discurso pesimista de Wild, Jaime Palomera (portavoz del Sindicato de Inquilinos de Barcelona) siguió defendiendo el modelo de Berlín y apostó por la aplicación de un sistema de regulación de precios del mismo tipo en España. Después de haber presentado el funcionamiento del Sindicato de Inquilinos de Barcelona, que lucha contra los abusos en la vivienda mediante la desobediencia civil y la lucha colectiva, criticó el índice de precios de la Generalitat porque se basa únicamente en los precios actuales del alquiler y "está legitimando los precios del mercado". Para él, habría que construir índices incorporando criterios sociales y con obligación de cumplimiento. Durante el debate con la sala, Wild volvió a decir que, según él, el sistema de regulación de los precios no era una buena idea porque no existen los recursos necesarios para obligar a los propietarios a cumplir la ley. A lo que Palomera y Burón respondieron sucesivamente que, incluso si estas medidas no son perfectas, les parecían necesarias como primer paso para una recuperación del control del sector de la vivienda por parte del actor público.

14 Por ejemplo, el incremento es posible si se hacen obras de rehabilitación o de eficiencia energética en el piso. 


\section{A modo de conclusión y discusión}

Con este foro, a dos meses de las elecciones municipales, el Ayto. de Barcelona quería enviar un mensaje fuerte demostrando su voluntad de seguir trabajando por el derecho a la vivienda. La estructura del foro fue coherente y permitió abordar todas las vertientes del tema de la vivienda en Barcelona. También permitió presentar todas las políticas puestas en marcha por el anterior equipo de gobierno de Barcelona (2015-2019) y las que pretende seguir en el nuevo mandato. Este gobierno quiere alinearse con los "estándares europeos" en materia de vivienda, desarrollando un mercado de la vivienda regulado y normalizado. Por eso, quiere crear un sistema de regulación de los precios del alquiler, luchar contra las viviendas vacías y las ocupaciones ilegales de vivienda para ponerlas en alquiler asequible. De acuerdo con otros representantes de administraciones territoriales (Generalitat y Estado), defiende una colaboración público-privada e intenta "corresponsabilizar" el sector privado para conducirlo a construir más viviendas asequibles como lo demuestra la MPGM de los $30 \%$ de vivienda protegida y el impulso del operador mixto Habitatge Metròpolis Barcelona. También quiere favorecer la participación ciudadana y colaborar con algunos colectivos militantes como lo demuestra los concursos de covivienda.

Pero más allá del balance del mandato y de las presentaciones de proyectos del IMHAB, este foro materializó algunas divergencias entre los actores de la vivienda presentes. El Ayto. de Barcelona defiende un modelo de políticas bastante intervencionista con un papel activo del sector público para controlar el mercado mientras que los otros representantes de instituciones públicas defendían más bien una visión de la colaboración público-privada basada en el incentivo y no la imposición rígida. De hecho, como se ha visto anteriormente, durante los debates con la sala algunos oyentes del foro comentaron que la voluntad de Burón de poner en marcha una colaboración público-privada basada en una corresponsabilización del sector privado chocaba con su propio discurso intervencionista y sus "medidas excepciones y radicales" para regular el mercado de la vivienda. Además, el consistorio intenta poner en marcha un mosaico de soluciones habitacionales inspiradas en otras ciudades del mundo que, para algunas de ellas, pueden considerarse contradictorias. ${ }^{15}$ También podemos señalar que el concepto de "colaboración público-privada" que usa el Ayto. aparece borroso porque mezcla promotoras privadas y asociaciones de habitantes (o colectivos militantes, cooperativas...), lo que se puede ver en la estructura misma del foro. ${ }^{16}$ Según varios colectivos militantes de Barcelona, el hecho de mezclar asociaciones de habitantes sin ánimo de lucro y promotores privados con ánimo de lucro en la misma categoría de "entidades privadas" puede ser peligroso a la hora de promocionar políticas de vivienda alternativa (Miralles Buil, 2018). Estos colectivos apuestan por una concertación "público-cooperativa-comunitaria" fomentando la economía social y solidaria y la noción de común, lo que los diferencia de la noción de "entidades privadas" convencionales (Dardot y Laval, 2015). No obstante, podemos notar un cierto alineamiento entre el Ayto. de Barcelona y algunas entidades sociales (PAH y Sindicato de inquilinos) sobre el tema de la regulación de precios de los alquileres, lo que demuestra por parte de estos actores una voluntad de defender la legitimidad de la administración pública en el control del sector de la vivienda.

En paralelo a la visión del gobierno municipal de un mercado de vivienda mayoritariamente en alquiler controlado por el sector público
15 Según algunas personas presentes en el foro con las cuales hemos podido hablar (actores diversos de la vivienda: promotores, investigadores, miembros de asociaciones...), mezclar medidas provenientes de países con estructuras públicas y jurídicas tan diferentes como Inglaterra, Francia, Alemania, Holanda y EEUU en un país con un contexto muy diferente como es el caso español puede parecer difícil.

16 En la sesión "Coproducir con otros agentes" se mezclaron proyectos de promotoras privadas convencionales y de asociaciones autogestionadas de habitantes. 
pero constituido y gestionado en colaboración con el sector privado, se materializó, durante el foro, otra propuesta que aposta por tenencias alternativas y autogestionadas por los colectivos militantes. Así, de Raquel Rolnik al representante del Sindicato de Inquilinos de Berlín Reiner Wild, pasando por Vanesa Valiño (Ayto. de Barcelona), los proyectos de vivienda cooperativa autogestionada (cooperativas, CLT...) fueron presentados como unas de las esperanzas más potentes para defender el derecho a la vivienda y a la ciudad (Lefebvre, 1968). Veremos durante los cuatros próximos años si el segundo gobierno municipal presidido por Ada Colau, reelegida como alcaldesa de Barcelona en junio de 2019, conseguirá sacar adelante el proyecto empezado en 2015. 


\section{Referencias}

Dardot, Pierre y Laval, Christian (2015). Común: ensayo sobre la revolución en el siglo XXI. Barcelona: Gedisa.

Ghekiere, Laurent (2008). Le développement du logement social dans l'Union européenne. Recherches et Prévisions, 94, 21-34.

Hernández Falagán, David (ed.) (2019). Innovación en vivienda asequible. Barcelona 2015-2018. Barcelona: Ajuntament de Barcelona. Recuperado el 13 de agosto de 2019 de: https:/ / ajuntament.barcelona.cat/barcelonallibres/sites/default/files/publicacions_fitxers/pdf_indexat_innovacion_vivienda_ asequible_cast.pdf.

Lefebvre, Henri (1968). Le Droit à la ville. Paris: Anthropos.

Lévy-Vroelant, Claire y Tutin, Christian (eds.), Le logement social en Europe au début du XXI siècle (pp. 99-112). Rennes: Presses universitaires de Rennes, Nueva edición [en línea]. DOI: 10.4000/books. pur.26577

Lopes de Souza, Marcelo (2006). Together with the state, despite the state, against the state. Social movements as 'critical urban planning' agents. City, $10(3), 327-342$.
Miralles Buil, Diego (2018). L'habitat coopératif, vecteur de nouveaux communs territoriaux à Barcelone. Espaces et sociétés, 175, 69-86.

Muxí, Zaida (2018). Mujeres, casas y ciudades: más allá del umbral. Barcelona: DPR-Barcelona.

Reinprecht, Chrisptoph (2010). Autriche: l'adieu à la classe ouvrière. En Lévy-Vroelant, Claire y Tutin, Christian (eds.), Le logement social en Europe au début $d u X X I^{e}$ siècle (pp. 99-112). Rennes: Presses universitaires de Rennes, Nueva edición [en línea]. DOI: 10.4000/books.pur.26599

Rolnik, Raquel (2018). La Guerra de los lugares: la colonización de la tierra y la vivienda en la era de las finanzas. Barcelona: Descontrol.

Sennett, Richard (2019). Construir y habitar. Ética para la ciudad. Barcelona: Anagrama.

Sequera Fernández, Jorge y Nofre, Jordi (2018). Shaken, not stirred: New debates on touristification and the limits of gentrification. City, 22(5-6), 843855.

Turner, John F.C., Golda-Pongratz, Kathrin, Oyón, José Luis y Zimmermann, Volker (2018). Autoconstrucción. Por una autonomía del habitar. Logroño: Pepitas.

Miralles Buil, Diego (2019). Balance del Foro de Vivienda y Rehabilitación de Barcelona (FHAR). Hábitat y Sociedad, 12, 123133.

<http://dx.doi.org/10.12795/HabitatySociedad.2019.i12.08> 


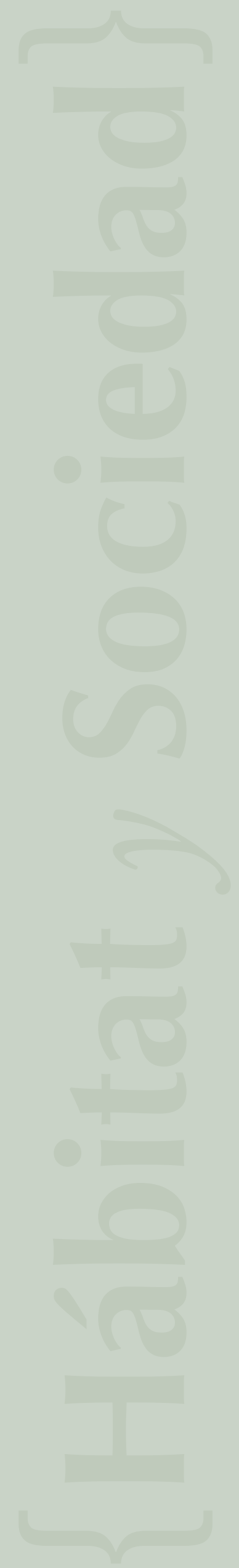

